\title{
The ill effects of World Wide Web on the Google Generation: An analysis and criticism of ways in which the World Wide Web is altering young learners' cognitive behaviors
}

\author{
Michele Wong Kung Fong \\ College of Visual Arts and Design, University of North Texas \\ 1201 West Mulberry Denton, TX, 76201. USA \\ Michele.wong@unt.edu
}

\begin{abstract}
While this paper values the different ways in which the World Wide Web is making data ubiquitous and more accessible, it questions some of its subtle yet destructive effects on the Google Generation/those born after 1993. This paper will look over the learners' interactions with online information, analyze the negative behavioral and psychological consequences caused by these interactions, question the consequences and in each case ask that designers of online experiences be more careful as they make design decisions when creating online interfaces. This paper poses the following research question: "How can the design of online activities on the World Wide Web positively affect the Google Generation's ability to focus, socialize, and think deeply? Most importantly, this presentation seeks to stir discourse that agree and/or disagree with the idea that the World Wide Web is negatively affecting the Google Generation's-those born after 1993-wellbeing. It hopes that discourse will lead to possible solutions to the current and increasing problem relating to attention, memory, patience, stress, and critical thinking in young learners.
\end{abstract}

World Wide Web. Learners. Cognition. Critical Thinking. Google Generation. Web Design. Information Design

\section{INTRODUCTION}

With scholarship in mind, the search engine was originally invented to support scientific research activities. In 1990, Archie, short for 'archives,' was the first search engine to be created. In 1980, Tim Berners-Lee's concept of hypertext's main purpose was the sharing and updating of information among researchers. Today's search engines still maintain the same goal of allowing users to access and share information. Technological advancements have made this process much faster and accessible to a larger demographic from many more access points-computers, television, game stations, and cellular telephones.

Search engines have increasingly become the wellspring for data and information as well as the venue for many types of transactions. The World Wide Web is the place one goes to find out lyrics to a song, to get directions to a concert destination, or to look up a recipe for apple pie. In any situation, users gravitate towards search engines to find answers and explanations, to learn who, what, when where, why, and how. These answers and explanations manifest themselves in different formsfrom images to videos, from casual forum conversation to scholarly articles. The range of tasks performed online ranges from trivial to significant.

In a study titled "Search Engine Users" that was carried out by the Pew Internet and American Life Project in 2005, 55\% of searchers say about half the information they search for is important to them and half is trivial. $28 \%$ of searchers say most of the information they search for is important to them and $17 \%$ of searchers say most of the information they search for is trivial.

The categories categories under which the 2002 AltaVista searches fell were:

(i) People, places or things 
(ii) Commerce, travel, employment, or economy

(iii) Computers or internet or technology items

(iv) Health or sciences

(v) Education or humanities

(vi) Entertainment or recreation

(vii) Sex or pornography

(viii) Society, culture, ethnicity or religion

(ix) Government (or military)

(x) Performing or fine arts (From AltaVista 2002)

Decades ago, the thirst for information would have encouraged people to leave their houses to seek answers. Some would go to the library for hours, immersing themselves in journals and encyclopedias. Those in need of medical care or reassurance would set up a doctor's appointment to seek advice and cure any concern. Anyone planning a trip would consult a travel agent to get the best fares.

Today, users quench their thirst for answers by googling. Search Engines, applications and websites have not only enabled easy and ubiquitous access to information, but they have also provided their users with more competitive services and choices. Sites like Expedia.com, Travelocity.com and CheapTickets.com are now the online manifestations of travel agents. Forums now act as online versions of community councils. Sites like WebMD have become our 24-hour doctor and Wikipedia is the new encyclopedia for many young learners.

What Expedia, WebMD and Wikipedia all have in common is their ability to provide instant answers to users' trivial and/or complex questions. No appointments have to be made, no driving is exercised and no expenses (other than the internet connection rates) are incurred as users jump from one webpage to another to browse for their answers.

\section{PROBLEM STATEMENT}

"The toll of Technology," an essay featured in Insight, the Magazine for Alumni and Friends of the Chicago School of Professional Psychology, makes a great argument for and against technology and its effects on users. It quotes Dr. Larry Rosen's research, which focuses on the positive and negative effects of technology on the Millennial Generation or the "Net Generation" (2009). Dr Rosen states the following regarding the different ways in which technology is shaping our young learners:

"We know that this generation sleeps less than any generation before, and we also know that media use leads to unhealthy eating, which leads to all forms of illbeing-including psychological problems, behavioral problems, attention difficulties, and physical symptomology" (2009).

Parents, educators and other researchers join Dr. Rosen as they confirm witnessing the different ways in which the Google Generation's well being-attention, memory, patience, stress, cognition-is continuously affected by their consumption of online information and the types of interactions they are experiencing with information.

\subsection{Attention Skills/Memory/Patience}

Anecdotally, restless, unfocused and scattered are common terms used by many concerned educators to describe today's undergraduate college learners. Most blame the learners' current behaviors on the amount of time they spend on social networking sites. Some assume that learners' "addiction" to/over-consumption of the online is affecting the way they think and behave in and outside of the classroom.

Researchers agree. In "Outdoors and Out of Reach, Studying the Brain," Matt Richtel (2010) writes that according to the Centers for Disease Control and Prevention (CDC), 
there is a correlation between the 3 percent annual jump-between 1997 and 2006-in diagnoses of Attention Deficit Hyperactivity Disorder and the increased media exposure by "children whose brains are not yet capable of processing a lightening-fast parade of visual images." Richtel pursues by saying that like other researchers, Mr. Strayer, a psychology professor at the University of Utah, claims that an understanding of how attention works could help attend to a variety of illnesses such as attention deficit disorder, schizophrenia and depression. (Richtel, 2010).

Consciously or unconsciously
conceptualizers,
programmers of online interfaces are
shaping users' online and offline
behaviors. It is important that they take the utmost care as they craft conditions for users' online experiences. There is always a desire to add elements to websites to make them "more interesting." However, excessive stimuli have negative effects on the brain. The first call for action pressed by this paper is to encourage conceptualizers, designers and programmers of online interfaces to inform themselves about how attention works as a pre-requisite to designing online interface. How can an understanding of how attention works inform the conceptualizers, designers and programmers of online interfaces as they create interfaces that are targeted towards the Google Generation? How can the science behind attention inform design decisions during the web design process?

\subsection{Time Management and Stress}

In another one of his article "Attached to Technology and Paying a Price," Matt Richtel (2010) shares that urges to juggle e-mails, phone calls and other information can inflict nicks and cuts on creativity and deep thought, interrupting work and family life. He further states that while some believe that multitasking makes them more productive, research shows that heavy multitaskers have more trouble focusing and shutting out irrelevant information which causes them to be more stressed (Richtel, 2010).

Learners that make up the Google Generation are known for their natural ability to multitask.

A survey titled "Generation $\mathrm{M}^{2}$ : Media in the Lives of 8- to 18-Year-Olds," released by the Kaiser Family Foundation (2010), "revealed that "8-18 year-olds devote an average of 7 hours and 38 minutes to using entertainment media across a typical day (more than 53 hours a week). And because they spend so much of that time 'media multitasking', they actually manage to pack a total of 10 hours and 45 minutes worth of media content into those $7 \frac{1}{2}$ hours" (Kaiser Family Foundation, 2010).

This paper also questions the implications of multitasking on learning and critical thinking and provokes thoughts to the following questions:

What kind of online strategies can be embedded in websites to promote productive learning in our learners? Should multitasking be blocked from the online or should new skill sets be developed by learners to counter the ill effects of multitasking? How do you block multitasking online? If impossible, what alternate solutions are we left with?

\subsection{Critical Thinking Skills}

In addition to negatively affecting learners' attention, memory, patience and stress level, their critical thinking skills are also being negatively impacted. A study conducted by the University College London found that those born after 1993 "lacked the critical and analytical skills necessary to assess the information they found mostly through search engines" (Gonsalvez, 2008). Echoing these findings, college educators are lamenting that there has been a decline in students' ability to take good notes, ponder about 
and resolve problems. Many say that students are also exhibiting a lack of patience and a constant need for answers to be handed to them instantly.

Maryanne Wolf of Tufts University explains, "...When a child learns to read, the brain builds pathways that gradually allow for more sophisticated analysis and comprehension...She calls that analysis and comprehension 'deep reading.' But that takes time, even if it's just a fraction of a second, and today's wired world is all about speed, gathering a lot of superficial information fast." Wolf questions the implications of increasing online reading performed by young children and she fears that the latter will lose their ability to reflect and question (Gonsalvez, 2008).

Similarly to Maryanne Wolf, who thinks that kids will need tailored instructions that will support them as they read in the digital world, this paper asks that online educational information designers, instruction designers, learning technologists, and curriculum developers join efforts to generate a new online learning experience that enhances reading comprehension and analysis.

While the Internet is making information accessible, it might not be providing the conditions needed for users to turn words into knowledge, draw inferences and analogies, and foster ideas. There could be a shift from search engines offering an environment that diminishes information processing to provide an environment and vehicle that encourages learners to think harder about the information being studied. A failure to promote this shift could result in a series of search engines that (maybe not intentionally) dumb down the next generation of learners by making them less autonomous and "not think."

Predictions showcased in a study, titled "Information Behaviour of the Researcher of the Future" (2008), commissioned by the British Library and the Joint
Information Systems Committee (JISC) provided an intricate analysis of how the specialist researchers of the future-the Google generation-are predicted to access and interact with online information in five to ten years. Educational concerns were raised regarding whether "having 'facts at their fingertips' and surfeit of information is at the expense of creative and independent thinking?" (British Library and JISC, 2008).

Because it is unlikely that the Internet will cease nor should it cease providing information, and because the Internet one of the main sources of information that the "Google generation" will be relying on, it is important that the disseminators and designers of online information provide conditions for independent and critical thinking in our future learners.

How should designers provide online information in ways that will encourage deep reading versus surface learning? If Nooks and iPads are likely to replace and/or become children's new textbooks, how can designers rethink information design and delivery in a way that will allow for the same cognitive behaviors that a printed book typically provides? Or what new cognitive behaviors can be encouraged and developed in this new learning ecology?

\section{CONCLUSION}

Search engines have become the online doors to data-the cheapest, most accessible and most used encyclopaedia/ textbook of this century. With search result lists now posing as the spines to the online page, providing any learner with instant information, designers as well as users of online need to be concerned about the implications of this new learning ecology. While this paper values easy access to information and competitive services that are being enabled by the World Wide Web, it finds it necessary for users, 
proponents and creators of online interfaces to rethink the way users interact with information so that the ill effects are minimized and instead cognitive behaviors are developed in the Google Generation.

\section{REFERENCES}

British Library and the Joint Information Systems Committee (JISCISCISC). 2008. Information Behaviour of the Researcher of the Future. http://www.slideshare.net/ (Retrieved on December 20, 2009).

(2009) The Toll of Technology. Insight Magazine. http://insightmagazine.org/2009/featured/the-toll-oftechnology/ (Retrieved on January 15,2011).

Fallows, D., (2005). A Search Engine Users. Pew Internet \& American Life Project.

http://www.pewinternet.org/Reports/2005/

Search-Engine-Users.aspx (Retrieved on December 10, 2009).

Foehr, U., Rideout, V., Roberts, D. (2009). Generation $\mathrm{M}^{2}$ : Media in the Lives of 8- to
18-Year-Olds. Kaiser Family Foundation. http://www.kff.org/entmedia/upload/8010.p df (Retrieved on March 12, 2011).

Gonsalves, A., (2008) Despite The Internet, Google Generation Lacks Analytical Skills. Information week. http://www.informationweek.com/news/inte rnet/search/showArticle.jhtml?articleID=20 5901358. (Retrieved on December 2, 2011).

Kommers, P., Jonassen, D., and Mayes, J. 1992. Cognitive tools for learning. London: Springer Verlag, 1.

Richtel, M., (2010) Your Brain on computers: Attached to Technology and Paying a Price. The New York Times. http://www.nytimes.com/2010/06/07/techn ology/07brain.html?ref=yourbrainoncomput ers (Retrieved on January 1,2011).

Ritter, M., (2008) Scientists concerned about effect of technology on brain. The Press Enterprise. http://www.pe.com/business/local/stories/P E Biz S webonly brain04.3d93418.html. (Retrieved on January 1,2011). 